\title{
SECOND LANGUAGE ACQUISITION AT THE INTERFACES
}

\author{
$\underline{\text { Abstract }}$ \\ In recent research on L2 acquisition, there has been considerable emphasis on interfaces \\ between the linguistic system and grammar external components, such as syntax/discourse, or \\ between different modules of grammar, such as syntax/semantics, syntax/morphology or \\ morphology/phonology. This has led to proposals that difficulties experienced by L2 learners can \\ be explained in terms of problems with integrating linguistic phenomena relevant to certain \\ interfaces. With some exceptions, there has been a tendency to consider at least some interface \\ phenomena as inherently problematic, while others are inherently unproblematic. This paper \\ provides an overview of L2 research on interfaces, comparing different interface domains. I \\ conclude that we must be wary of assuming that all linguistic interfaces are equally problematic \\ or unproblematic or that different linguistic phenomena pertaining to the same interface will \\ necessarily behave alike.
}

\section{$\underline{\text { Keywords }}$}

syntax/discourse interface; syntax/semantics interface; semantics/pragmatics interface; syntax/morphology interface; phonology/morphology interface. 


\section{$\underline{1 . \text { Introduction }}$}

In the past decade or more, there has been considerable investigation into the ways in which different components of the grammar interact with each other, as well as the grammatical effects of such interactions (see, for example, Jackendoff, 1997, 2002, 2007; Reinhart, 2006; papers in Ramchand and Reiss, 2007). There has been increasing emphasis on grammar-internal interfaces, such as the interface between syntax and semantics or syntax and phonology, as well as grammar-external interfaces, such as the relationship between syntax and discourse. In recent language acquisition research (whether this concerns first language (L1), second language (L2) or bilingual acquisition), there has been a parallel emphasis on interfaces, with a particular consideration of whether interface properties are in some sense harder to acquire or subject to more persistent difficulties than properties relating to 'pure' (non-interface) domains, such as 'narrow' syntax.

A particularly influential perspective on interfaces in L2 acquisition addresses the nature of the endstate knowledge of highly proficient L2 speakers, making comparisons between different kinds of interfaces in near-native grammars. This position has been advanced by Sorace and colleagues for some time and has been termed the Interface Hypothesis by Sorace and Filiaci (2006). The idea is that, in so far as near-native speakers have problems at all, these are likely to be associated only with certain interfaces. The hypothesis has developed over time. The original proposal, which I will refer to as Version 1, compares narrow syntax to interface syntax in general (e.g. Sorace, 2005, 2006), arguing that narrow syntax (with its uninterpretable features, which are internal to the computational system) is in some sense more privileged than interface syntax. A more recent version (Version 2) compares external interfaces (where the syntax interfaces with other cognitive domains) to internal ones (where only formal properties of the grammar are implicated) (e.g. Sorace and Filiaci, 2006; Sorace and Serratrice, 2009; Tsimpli and Sorace, 2006), proposing that external interfaces result in greater difficulties than internal ones. Both versions of the Interface Hypothesis take the syntax/discourse interface (particularly 
interpretable features relating to this interface) to provide a significant source of residual but lasting non-nativeness in the grammars of endstate L2 speakers, revealed in the form of indeterminacy, optionality and long-term L1 effects. For example, Belletti et al. (2007) highlight the incomplete mastery of discourse constraints on the realization of topic and focus by nearnative Italian speakers whose L1 is English, with consequent non-native use of overt subject pronouns and postverbal subjects.

The presumed status of grammar internal interfaces depends on which version of the hypothesis is under consideration. On Version 1, for example, the lexicon/syntax interface is explicitly considered to be problematic (Sorace, 2006). Presumably, the syntax/semantics interface should result in difficulties as well, since interface syntax is in general assumed to be problematic on this version. However, on Version 2, the syntax/semantics interface is taken to be a prime example of an unproblematic internal interface, while other internal interfaces are not explicitly discussed (e.g. Sorace and Serratrice, 2009; Tsimpli and Sorace, 2006).

The claim that non-target behaviour is particularly likely to be found with linguistic phenomena pertaining to the syntax/discourse interface has also been examined more broadly, with respect to other contexts of language acquisition and loss, including the following: advanced L2 learners who are not near-native (e.g. Hertel, 2003; Lozano, 2006); L2 learners of lower proficiency still in the course of L2 development (e.g. Belletti and Leonini, 2004; Hertel, 2003); L1 acquirers (e.g. Schaeffer, 2000; Tedeschi, 2009); simultaneous bilingual acquirers (e.g. Hulk and Müller, 2000; Paradis and Navarro 2003; Serratrice et al., 2004); heritage language acquirers (Montrul 2004; Montrul and Louro, 2006); cases of L1 attrition (e.g. Tsimpli et al., 2004). Results from several of these studies suggest that the problems experienced by steady state near-native L2 speakers do not arrive out of the blue; rather, they show up during the course of language acquisition and during language loss, in younger and older learners. What is noteworthy is the persistence of non-native linguistic behaviour associated with this particular interface. 
In this paper, I will suggest that the Interface Hypothesis has sometimes been interpreted in a manner that is too sweeping and that the time has come for a more nuanced approach (see also Lozano, 2009; Sorace, 2009; White, 2009; Yuan, 2010). We must be wary of assuming that: (i) All interfaces are equally problematic or unproblematic for language learners; (ii) external interfaces provide the main locus of L2 difficulties; (iii) different linguistic phenomena pertaining to the same interface will necessarily behave alike.

In particular, I will suggest that it is inappropriate to make across-the-board generalizations for L2 learners and L2 speakers (henceforth, L2ers) about ease or difficulty in acquiring or using linguistic properties relating to interfaces, tempting though it may be to do so. Indeed, it has proved very hard to disentangle problematic from unproblematic interface phenomena in a principled way (a laudable aim of the Interface Hypothesis). Nevertheless, it does appear to be the case that the need to integrate different sorts of linguistic information can be particularly challenging (though not insurmountable). I will suggest that some aspects of nontarget performance in interface domains reflect representational differences between interlanguage grammars and native speaker grammars, while other aspects reflect processing or computational difficulties (see Hopp, 2007; Sorace, 2006, 2007, 2009).

\section{Interfaces: some definitions}

As the term interface has been used in a number of ways within linguistic theory and within acquisition theory, some clarification is in order. Sometimes, interfaces are understood as levels of representation; alternatively, they are taken to be points of mapping between levels of representation. There is also disagreement as to whether typical interface phenomena are or are not represented in the grammar as such. Clearly, perspectives on interfaces in L2 acquisition will differ, depending on how the term is understood.

The original interfaces (so to speak) are Logical Form (LF) and Phonetic Form (PF). These are seen as levels of representation (e.g. Chomsky, 1995), whose function is to interface with cognitive systems external to the grammar, namely the conceptual-intentional system 
(meaning) and the articulatory-perceptual system (sound) respectively. It is not clear that interfaces in the sense of LF and PF are what L2 researchers have in mind; in other words, researchers have not claimed that $\mathrm{PF}$ and $\mathrm{LF}$ are problematic as such. Indeed, on the assumption that LF, at least, is universal and uniform for all languages, difficulties are not, in fact, expected with this interface level, though learners might have LF representations of sentences which do not coincide with the representations of native speakers. Under this conception, an interface does not have be acquired: one does not acquire levels of representation, since these are part of the grammatical apparatus (given by UG) that language acquirers bring to bear when dealing with the target language. While learners have to acquire linguistic phenomena pertaining to interfaces and may represent them differently from native speakers, this does not imply that they have to acquire the interface itself. Nevertheless, the debate in the acquisition literature is often (and somewhat misleadingly) phrased in terms of ease or difficulty in acquiring interfaces.

A prevalent conception of interfaces in L2 research sees them as involving interaction or mapping between linguistic modules or representations. Whenever there is a mapping between different levels of representation, an interface between those levels is necessarily implicated. For example, the syntax of a sentence must be mapped onto its semantics, hence the syntax/semantics interface; the syntax of a sentence also must mapped onto the phonology, hence the syntax/phonology interface; and the syntax of a sentence must be mapped onto the discourse, hence the syntax/discourse interface. What has to be acquired is L2-appropriate mappings and this may prove to be problematic, at least for some interfaces (see Lardiere, 2000); integrating different levels can result in mapping problems, or mapping in L2 grammars may differ from mapping in adult native speaker grammars.

Terms like syntax/semantics interface or syntax/phonology interface imply that linguistic modules are being considered as a whole but of course the issue of integration arises for the representation of every utterance. Indeed, one of the implications of phase theory (Chomsky, 2001), presumably, is that interfaces will come into play at every phase within an utterance. (See López (2009) for a recent instantiation of this position.) Jackendoff $(1997,2002,2007)$ points 
out that it is an oversimplification to treat LF and PF as the only interfaces, proposing instead a 'parallel architecture' whereby there are multiple interfaces, internally and externally, operating in tandem. In his system, there are interface rules which provide correspondences between different levels/types of representation. This appears to be equivalent to the conception of interfaces as points of mapping between representations. (See Slabakova (2008) for a reconciliation of the minimalist approach and Jackendoff's view.) Once again, the implication for acquisition is not that interfaces have to be acquired as such. But correspondence rules have to be acquired and L2ers' correspondence rules might not correspond to native-speaker rules.

It turns out that there is disagreement as to whether certain interface phenomena are included in the computational system and, if so, which ones (Reinhart, 2006). For example, the minimalist framework does not accommodate discourse, pragmatics and information structure within the computational system (see Jackendoff, 1997; Erteschik-Shir, 2007; Slabakova, 2008). Instead, these domains are treated as being outside the grammar proper, not part of the computational system but rather part of conceptual structure or information structure. These systems may be further decomposed into subsystems, all of which must interface with the grammar; see Reinhart (2006) for proposals relating to the conceptual-intentional system.

On the other hand, a number of researchers argue that at least some phenomena relating to the syntax/discourse interface, including topic and focus, are represented in the grammar proper, for example as functional categories in the cartographic system of Rizzi and colleagues, where $\mathrm{CP}$ is divided into a number of categories, such as ForceP, FiniteP, TopicP, FocusP (e.g. Belletti, 2004; Rizzi, 1997) or as syntactic or lexical features (e.g. Büring, 2007; Erteschik-Shir, 2007; Jackendoff, 1972; Zubizarreta, 1998). With respect to the Interface Hypothesis of Sorace and colleagues, it has been argued that certain interpretable features, such as \pm topic shift, are the source of continuing problems at the syntax/discourse interface (e.g. Sorace, 2003, 2009). 


\section{Historical perspectives}

L2 research relating to what we now think of as interfaces predates current interest in this topic, in some cases, by many years. Here I will consider some examples, involving what are now known as the syntax/discourse interface and the syntax/semantics interface.

The first example relates to the distribution of null versus overt subjects in null subject languages like Italian and Spanish, an issue that has attracted considerable attention more recently as a central interface issue in L2 acquisition. In the context of the null subject parameter (Jaeggli, 1982; Rizzi, 1982), most L2 research on this parameter in the 1980s concentrated on its syntactic effects and the question of whether or not L2 learners can acquire new parameter values when the L1 and L2 differ in their settings (e.g. Liceras, 1988; Phinney, 1987; White, 1985). Liceras (1988) pointed out that the distribution of null and overt subjects in languages like Spanish is governed not only by a syntactic parameter setting but also by stylistic (or what we would now think of as discourse) constraints. Predating current views by many years, Liceras suggested that L2 learners of Spanish who have appropriately reset the null subject parameter to its [+null subject] value may nevertheless fail to observe additional discourse constraints on null subject use, resulting in overuse of overt subjects in discourse contexts where a null pronoun would be appropriate (where there has been no change in topic, in current terms). Such a differentiation between syntax and discourse is what Sorace and colleagues have investigated more recently, with similar results, namely overuse of overt pronouns in contexts where they should be null. ${ }^{1}$

Another aspect of L2 null and overt subject use that has been investigated in the past involves a comparison of the discourse-related properties of topic and focus. Though not using the term interfaces, Perez-Leroux and Glass $(1998,1999)$ do make explicit comparisons between the acquisition of purely syntactic or semantic constraints on overt pronouns versus choices affected by which NP is the topic or focus in the sentence. Using elicited production tasks

\footnotetext{
${ }^{1}$ However, see Montrul (2004), Gürel (2006) and Lozano (2009) for evidence of overuse of null subjects as well.
} 
(translation and question answering), they found that L2 learners of Spanish at all levels of proficiency appropriately used null pronouns instead of overt pronouns in bound variable contexts, which are governed by a universal constraint against overt pronouns (Montalbetti, 1984). When topic and focus were manipulated, on the other hand, there were proficiency effects, such that only the advanced group fully distinguished between the need to use null pronouns in topic contexts and overt pronouns in focus contexts. (See Gürel (2006) and Rothman (2009) for more recent comparisons of the same phenomena in L2 Turkish and L2 Spanish, respectively, this time couched as an interface issue.)

The final example of earlier research implicating what is now seen as an interfaceconcerns syntax/semantics, in particular, subtle differences in interpretation of adjectives in Romance languages depending on word order differences. This was one of many issues investigated by Coppieters (1987) who explored the issue of near-native competence in L2 French, arguing that near-native speakers diverge from native speakers in their underlying linguistic competence. This claim is based on the investigation of a number of linguistic phenomena, including subtle interpretive differences that arise depending on whether adjectives in French occur in prenominal or postnominal position. Prenominal adjectives have a less literal interpretation than postnominal, as shown in (1) (example from Coppieters).

(1) Hier, ce honteux journaliste/ce journaliste honteux est encore venu chez nous. Yesterday, this shameful journalist/this ashamed journalist came to our house again. Coppieters found that near-native L2ers were unable to articulate the interpretive differences between prenominal and postnominal adjectives and were often totally unaware of them. In current terms, this would suggest a problem with the interface between word order (a syntactic property) and interpretation (a semantic property). This issue has recently received attention again, couched explicitly in interface terms. Results from Anderson (2008) for L2 French and Rothman et al. (2010) for L2 Spanish suggest that L2 learners do in fact acquire the appropriate subtle contrasts in meaning, although often not until they have reached higher levels of proficiency. 
One possible reason for differential success across these studies is methodological. Coppieters employed a highly metalinguistic means of assessing linguistic competence, asking L2ers to articulate the meanings of certain utterances, with no contexts supplied. ${ }^{2}$ In contrast, one of the tasks employed by Rothman et al. (2010) was a semantic interpretation task, where learners had to select an interpretation without having to describe or explain it. In a production task, Rothman et al. provided contexts to try to elicit appropriate word orders and Anderson (2008) provided contexts in a grammaticality judgment task. Greater success in tasks involving contexts suggests, not surprisingly, that 'out of the blue' sentences are not the best way to investigate L2 knowledge of an interface involving semantic interpretation.

\section{Current perspectives: comparing interfaces}

We turn now to L2 research which explicitly sets out to investigate interfaces of one kind and another. In the late 1990s, several interface areas were investigated independently. These included the syntax/discourse interface (Sorace and colleagues), the syntax/semantics interface (Dekydtspotter and colleagues) and the syntax/morphology/lexicon interface (Lardiere, 1998; Prévost and White, 2000a, b). More recently, additional interfaces have been investigated, as described below.

A comparison of L2 performance at different interfaces suggested that they do not result in the same level of difficulty, thus in part motivating the Interface Hypothesis. For example, as far as the syntax/semantics interface is concerned, in a series of studies, Dekydtspotter and colleagues investigated a number of different interface properties, in L2 learners of French at different proficiency levels. In general, their results show that once L2ers acquire relevant syntactic properties exemplified in French but not in English (the L1), the interpretive consequences 'fall out' for free, so to speak. In contrast, the syntax/discourse interface is often identified as being in some sense inherently problematic. Since syntax/semantics involves a grammar-internal interface, whereas syntax/discourse involves a grammar-external interface,

\footnotetext{
${ }^{2}$ For a critique of Coppieters's methodology, see Birdsong (1992).
} 
differential success at these two interfaces helped to motivate Version 2 of the Interface Hypothesis.

\subsection{Syntax/discourse}

The syntax/discourse interface (an external interface) has probably received more explicit focus in L2 research than any other interface (with the possible exception of the syntax/semantics interface). There has been extensive investigation of how L2 speakers of null subject languages realize topic and focus, particularly on how these discourse properties are realized in terms of subjects (null or overt) and word order (preposed or postposed subjects). Papers by Sorace and colleagues demonstrate, using a variety of methodologies, that even near-native speakers of Italian fail to fully master discourse constraints on realization of topic and focus, suggesting long-term and permanent problems at the interface between syntax and discourse (e.g. Belletti et al. 2007; Sorace and Filiaci, 2006; Tsimpli and Sorace, 2006). Errors and/or inappropriate usage are not extensive but they are persistent. Other researchers have reported similar findings at lower levels of proficiency for both L2 Italian and L2 Spanish (Belletti and Leonini, 2004; Hertel, 2003; Lozano, 2006).

Another study indirectly reinforces the point that this interface is generally problematic. In an investigation of L2 acquisition of Dutch (a language which requires overt subjects), Roberts et al. (2008) report that Turkish speakers (null subject L1) in contrast to German speakers (L1 similar to Dutch) are significantly more likely to choose a sentence external referent for a potentially ambiguous overt pronoun than either the German L2ers or the Dutch native speakers. This suggests L1 influence, since in Turkish there is a discourse preference for overt pronouns to take external referents. However, in an eye-tracking task, both L2 groups showed a disadvantage (compared to native speakers), suggesting that processing of overt pronouns which depend on discourse for resolution is problematic regardless of L1.

The results so far discussed raise several questions: (i) Is the syntax/discourse interface globally problematic or are difficulties a consequence of the particular phenomena which have been chosen for investigation, with the concentration so far mainly being on syntactic and 
discourse properties of null subject languages? (ii) The Interface Hypothesis addresses only one external interface, namely syntax/discourse, as we have seen. Are difficulties also experienced at other external interfaces, for example, the semantics/pragmatics interface $?^{3}$ (iii) To what extent can difficulties be attributed to methodological concerns?

With respect to the first question, it appears that phenomena pertaining to the syntax/discourse interface are not inevitably a source of long-term non-nativeness and optionality. Consider, for example, clitic doubling, which has been argued to implicate the syntax/discourse interface, since clitic doubling occurs in cases where DPs are topicalized. Some researchers have reported that L2ers have lasting difficulties in working out the relevant constraints on clitic doubling, whereas others find that acquisition of appropriate clitic doubling is not problematic in the longer term.

Clitic doubling of topicalized objects (known as clitic left dislocation) is a phenomenon that occurs in a number of languages. For instance, in Spanish, when a topic occurs in the left periphery of the clause, a clitic marks the position in which the topic must be interpreted, as shown in (2a). Crucially, there is a specificity requirement: the clitic is obligatory when the topic is specific; see (2b). However, when the topic is non-specific, clitics are prohibited; compare (2c) and (2d) (examples from Valenzuela 2006). Other languages behave similarly: Greek also has clitic doubling with topics, as shown in (3) (Tsimpli and Sorace, 2006; Parodi, 2009), as does Bulgarian, as shown in (4) (Ivanov 2009). In both cases, clitic doubling is subject to a specificity constraint, as it is in Spanish. As Ivanov points out, in Bulgarian, clitic doubling is required with topicalized NPs but infelicitous with NPs that are focused, as in (4b).

(2) a. El libro, lo leí the book, it-CL read-1S

'I read the book.'

b. *El libro, leí

\footnotetext{
${ }^{3}$ It is not entirely clear to me what the difference is, if any, between terms like discourse and pragmatics. These expressions tend to be used interchangeably in the L2 literature.
} 
the book, read-1S

c. Un libro, leí

A book, read-1S

'I read a book.'

d. *Un libro, lo leí

a book, it-CL read-1S

(3) Ton Petro ton-sinandise I adhelfi mu

The-ACC Petro him-CL-met-3S the-NOM sister my

'Petro, my sister met him.'

(4) a. Ivan go vidja sutrinta

Ivan him-CL see-past-1S in the morning

'Ivan, I saw him this morning.'

b. *Vidjah go Ivan

see-past-1S him-CL Ivan

'I saw Ivan'

Investigation of the L2 acquisition of clitic doubling has yielded mixed results. Using a variety of tasks, including grammaticality judgments and two tasks involving contexts (sentence completion and sentence selection), Valenzuela $(2005,2006)$ shows that near-native speakers of Spanish, with English as L1, acquire syntactic constraints on clitic left dislocation with relative ease. At the same time, they fail to acquire the constraint which determines that nonspecific topics may not occur with clitics. In other words, they produce and accept sentences like (2d), overusing clitic doubling. Tsimpli and Sorace (2006) report a different problem, namely, the underuse of clitic doubling by Russian-speaking learners of Greek, even at advanced levels. So far, then, these results contribute to the conception of the syntax/discourse interface as problematic, particularly the realization of topics and associated properties. Some very advanced 
L2ers fail to observe constraints on clitic doubling of topic NPs, adding to the research that has already shown that other realizations of topic are problematic, such as overuse of overt pronouns, as discussed above.

In contrast to these results, Ivanov (2009) and Slabakova and Ivanov (this issue) report that advanced English-speaking learners of Bulgarian do know the discourse constraints on clitics (whereas intermediate level learners do not). In a task somewhat similar to Valenzuela's sentence selection task (in that L2ers have to assess the appropriateness of certain sentences in a given context), advanced L2ers perform like native speakers in permitting clitic doubling when the NP in question is a topic and excluding it when the NP is in focus. Parodi (2009), using grammaticality judgment data, also shows that advanced learners of Spanish distinguish between clitic left dislocation with definite versus indefinite topics, like native speakers, whereas advanced learners of Greek fail to do so.

These differing results with respect to the same phenomenon suggest that it would be a mistake to assume that the syntax/discourse interface as a whole is necessarily problematic, or even that realization of topics (and associated properties) is necessarily liable to result in nonnative behaviour. Rather, it appears that problems are construction-specific instead of across-theboard, and possibly language-specific as well, in that it appears to make a difference as to which languages are the L1 and the L2. Indeed, it is not entirely clear that only the syntax/discourse interface is implicated in clitic left dislocation. Three different things need to be integrated: discourse (presence of a topic), syntax (presence or absence of a clitic associated with the topic, and positioning of that clitic), and semantics (whether or not the topic is specific). In other words, the interface is between syntax, semantics and discourse. Ivanov's subjects, who were successful, were tested on clitic left dislocation and topicality but not on specificity, whereas Valenzuela's subjects were tested on all three properties and proved to be less accurate (like Parodi's L2 Greek group). It could be that the more interfaces involved, requiring integration of more material, the harder it is to perform in the native speaker range. Another possibility is that at least some of the differences in the results can be accounted for in terms of the different 
methodologies involved. (See also, Slabakova and Ivanov, this issue.) However, this cannot be the whole story, since Valenzuela and Parodi both used grammaticality judgments but report different results, while Valenzuela and Ivanov both used sentence selection, with differing results. We return to this issue in the discussion.

With respect to the second question as to whether all external interfaces are a source of difficulties for L2ers, we turn to a consideration of recent research on the semantics/pragmatics interface, which examines L2 acquisition of scalar implicatures.

\subsection{Semantics/pragmatics}

Many sentences are interpreted in terms of considerations that go beyond strict semantics. Conversational maxims (Grice, 1989) come into play, such that speakers try not to be over- or under-informative. Expressions like some and all form an implicational scale (Horn, 1972), resulting in scalar implicatures, with the stronger term, all, implying the weaker term, some, but not vice versa. Although some could logically mean some and possibly all, it is not usually interpreted in that way. Rather, if the weaker term is used, the stronger one is assumed not to hold. For example, if a speaker utters a sentence like (5a), the hearer infers that $(5 \mathrm{~b})$ was not intended; rather, $(5 \mathrm{c})$ is the intended meaning.

(5) a. Some elephants have trunks.

b. All elephants have trunks.

c. Some but not all elephants have trunks.

Slabakova (2007, in press) investigates sensitivity to scalar implicatures in the L2 of Korean-speaking learners of English, who took a grammaticality judgment task previously devised by Feeney et al. (2004) to test English-speaking adults and children (based on Noveck 2001). In addition, the task was translated into Korean and administered to native speakers. Slabakova found differences between Korean-speakers' performance in their L1 and their L2, as well as differences between their L2 English performance and that of child and adult English speakers: the L2ers were more likely to give responses indicating that the implicature had been computed than the native speaker groups were. In other words, they rejected sentences like (5a) 
about $60 \%$ of the time, in contrast to the other groups who accepted these about $65 \%$ of the time. ${ }^{4}$ The results suggest that L2ers do not have problems computing implicatures as such, since their predominant response was the one that showed that the implicature had been calculated. Slabakova argues that the difference between native speaker and L2 responses reflects the fact that, due to diminished processing resources, L2ers are less able to conjure up logical alternatives and so stick with the original implicature (some implies not all, so sentences like (5a) are false).

Lieberman (2009) takes up the issue of processing resources that might be involved in computing implicatures, investigating cases which are computationally demanding even for native speakers, namely indirect implicatures such as those in (6), which involve a scale reversal. Whereas use of all normally implies that the weaker term some would be inappropriate, in downward entailing contexts involving a negative operator, as in (6a), the relationship is reversed, such that some is the intended meaning, just like (6b).

(6) a. Max didn't read all of the books.

b. Max read some of the books.

Gillingham (2007) has shown that native speakers of English find it harder to compute indirect implicatures, as in (6a), compared to direct implicatures, as in (6b). Lieberman (2009) tested L2 learners of English whose L1 was Japanese. They were presented with short written scenarios, each followed by a sentence to be judged which was infelicitous in that context. Lieberman reports that L2ers have even greater difficulty than native speakers with implicatures in such cases, suggesting that there is indeed a processing problem involved for computing implicatures in downward entailing contexts. Furthermore, when the processing load was lightened by presenting subjects with two sentences to choose between, one felicitous and the other infelicitous, the L2ers had no difficulty in picking the one which was appropriate for the context, even if it involved cases like (6a); their performance was indistinguishable from native speakers. Lieberman, like Slabakova, argues that L2ers do not in fact have problems computing

\footnotetext{
${ }^{4}$ Given that the native speakers performed somewhat unexpectedly (giving logical answers more often than computing implicatures), it is not entirely clear how to interpret the results.
} 
implicatures as such; they do, however, have problems processing downward entailing contexts (as do native speakers but to a lesser extent). In other words, it is not the case that the L2ers fail to access the relevant pragmatic knowledge.

To summarize so far, results investigating external interfaces like the syntax/discourse and semantics/pragmatics interface have yielded differing results. In some cases, lasting nonnative performance is reported, in other cases not; this appears to be true within and across interfaces. What also emerges is that it is not necessarily the case that L2ers' linguistic representations are 'defective'; but the need to integrate different kinds of linguistic properties may subject L2ers to particular processing pressures. We return to this issue below.

\subsection{Syntax/semantics (not to mention morphology)}

Turning now to the syntax/semantics interface (a grammar-internal interface), this interface was first drawn to people's attention by the work of Dekydtspotter and colleagues who have explored a variety of subtle interpretive contrasts that depend on word order variation permitted in French (the L2 in these studies) but not English (the L1). These researchers have conducted numerous experimental studies, investigating different issues, including process/result nominals (Dekydtspotter et al., 1997), quantification (Dekydtspotter and Sprouse, 2001;

Dekydtspotter et al., 2001), extraction of combien (Dekydtspotter et al., 2001) and quelque chose (Dekydtspotter and Hathorn, 2005), amongst other phenomena. Results have consistently shown that L2 learners exhibit very subtle knowledge which they have not been taught and which is not at all obvious in the L2 input. Once L2ers get beyond L1 transfer and accept word orders which are not permitted in the L1, they show (unconscious) knowledge of subtle interpretive distinctions associated with these word order differences that hold only for the L2.

These results may have given the impression that the syntax/semantics interface is inherently unproblematic, something that is not unexpected if LF and the computational system are universal (Dekydtspotter et al., 1997). Indeed, absence of problems at this interface has been assumed in Version 2 of the Interface Hypothesis to indicate that the syntax/semantics interface 
is unlike the syntax/discourse interface (Sorace and Serratrice, 2009; Tsimpli and Sorace, 2006). In the light of such findings, then, we can ask questions which are the inverse of those raised above for the syntax/discourse interface: (i) Is the syntax/semantics interface necessarily unproblematic or are the successes so far reported a consequence of the particular phenomena which have been chosen for investigation? (ii) Are other internal interfaces which involve the integration of syntax with other components of the grammar also unproblematic? According to Version 1 of the Interface Hypothesis, the syntax/lexicon and syntax/phonology interfaces, for example, are expected to lead to difficulties, precisely because they involve mappings beyond narrow syntax. According to Version 2, they might be expected to be unproblematic because they involve internal interfaces, just like the syntax/semantics interface.

With respect to the first question, some recent studies on indeterminate phrases in L2 Korean (Choi and Lardiere 2006), L2 Japanese (Umeda, 2008) and L2 Chinese (Yuan, 2008, 2010) are relevant. In wh-in-situ languages like Korean, Japanese and Chinese, wh-expressions are indeterminate and have different interpretations, depending on morphological and syntactic properties. In Korean and Japanese, particles play a crucial role in the interpretation of indeterminate wh-expressions. On the one hand, wh-phrases can, like their English counterparts, receive an interrogative interpretation, in simple or embedded wh-questions (equivalent to who, what, etc). On the other hand, the same lexical items can be interpreted as indefinites, either universal (e.g.everyone), existential (e.g. someone) or as negative polarity items (e.g. anyone). Crucially, in the case of Korean and Japanese, the interpretation is dependent on (obligatory) particles ( $c i$ and $t a$ in Korean; $k a$ and $m o$ in Japanese). In Chinese, on the other hand, there is an optional wh-particle, ne, but the indefinites do not have corresponding particles. In addition, there are syntactic requirements on the indefinite interpretations, including a locality requirement in Japanese and a c-command requirement between the indefinite and its licensor in Chinese. These properties are illustrated in (7) for Korean, from Choi and Lardiere (2006), (8) for Japanese, from Umeda (2008), and (9) for Chinese, from Yuan (2008, 2010). In each case, the (a) version shows a wh-question, while the (b) and (c) versions show indefinites. (The relevant 
particles are underlined; in Japanese and Korean, a sentence may contain more than one of these particles.)

(7) a. John-un Mary-ka mues-ul sassnun-ci an-ta John-TOP Mary-NOM what-ACC bought-PRT know-PRT 'John knows what Mary bought.'

b. John-un Mary-ka mues-ul sass-ta-ko an-ta John-TOP Mary-NOM what-ACC bought-PRT-C know-PRT

'John knows that Mary bought something.'

(8) a. John-wa nani-o kaimasita-ka?

John-TOP what-ACC bought-PRT

'What did John buy?'

b. Dare-ka-ga ringo-o tabemasita

who-PRT-NOM apple-o ate

'Someone ate an apple.'

c. Dare-mo-ga ringo-o tabemasita

who-PRT-NOM apple-o ate

'Everyone ate an apple.'

(9) a. Ni xiang mai shenme (ne)?

you want buy what (wh-Q)

'What do you want to buy?'

b. Wo shenme dou xiang mai

I what each want buy

'I want to buy everything.'

c. Wo bu xiang mai shenme

I not want buy what

'I don't want to buy anything.'

It turns out that $\mathrm{L} 2$ acquisition of indeterminates is not at all easy for native speakers of English. ${ }^{5}$ Choi and Lardiere (2006) for Korean and Umeda (2008) for Japanese investigate how

\footnotetext{
${ }^{5}$ L2 acquisition of Japanese by Chinese speakers (Umeda 2008) or Chinese by Japanese speakers (Yuan 2007) also proves to be problematic with respect to mastering the crucial roles of particles in licensing whexpressions. In Umeda's study, the Chinese-speakers turned out to be less successful at acquiring the relevant properties of Japanese than the English speakers were.
} 
L2ers interpret sentences with wh-interrogatives or wh-indefinites and their associated particles. By use of tasks (such as truth value judgments, translation and grammaticality judgments) where a context is given which sets up one or other interpretation, these researchers show that L2 learners often assume that indeterminate phrases have a wh-interrogative interpretation, regardless of which particle appears in the utterance. That is, given contexts motivating either an interrogative or an indefinite interpretation, they get the interrogatives right and the indefinites wrong, performing much better on cases like (7a) and (8a) than on (7b), (8b) or (8c). They fail to realize that the interpretation varies, depending on the form and position of the associated particle. Indeed, very few L2ers succeed in this domain. Even though the particles under investigation occur in the L2 input, L2ers have considerable difficulty in realizing their crucial role. The subtle interpretive differences between the L1 and the L2 require a high level of proficiency before they are mastered, if they are mastered at all.

As far as L2 Chinese is concerned, Yuan (2008, 2010) examines wh-expressions used as existential polarity words (see (9c)). These expressions occur in a limited number of non-factive syntactic environments, licensed by negation, the yes-no question particle $m a$, conditionals, uncertainty adverbs, etc. Yuan investigates seven such environments and shows that L2 learners of Chinese (L1s English and Japanese, ranging from beginners to advanced proficiency) acquire some but not all of the licensing possibilities for Chinese existential polarity words. In other words, in some cases, they fail to establish a relation between a potential licensor and a licensee. In consequence, Yuan argues that not only is the syntax/semantics interface not treated in a uniform manner in interlanguage grammars but that, even within the same construction (in this case, licensing of existential polarity items), there is differential success, suggesting that interfaces should not be viewed holistically.

Why is it that indeterminate expressions in these languages cause such difficulties for L2ers? Slabakova $(2008,2009)$ discusses successes and failures of L2 learners in the semantic domain and proposes the Bottleneck Hypothesis. Her claim is that semantic primitives and syntactic operations are universal. When syntax and semantics do not interface smoothly, the 
reason is a bottleneck caused by failure to fully master associated functional morphology. In other words, L2 learner difficulties are attributed to problems in interfacing between meaning and morphological realization. Slabakova (2009: 282) suggests that 'learning a second language entails learning the new configurations in which the various interpretable and uninterpretable features are mapped onto the target language inflectional morphology'. This is similar to Lardiere's $(2005,2008,2009)$ proposal that L2ers have problems with feature reassembly, as discussed below. Extending these ideas to the case in point, it is possible that some such bottleneck affects interlanguage representation of Korean and Japanese particles, preventing them from being interpreted in a native-like way. Indeed, Choi and Lardiere (2006), Lardiere (2009) and Umeda (2008) explain non-native performance on indeterminates in L2 Korean and Japanese in terms of failure to reconfigure features.

Does this mean that bottlenecks are inevitable and insurmountable in cases where feature reassembly is required? Again, this seems to depend very much on the particular properties under investigation. Consider, for example, the acquisition of English articles by native speakers of languages without articles such as Mandarin, Russian or Turkish. In such cases, assuming that the languages in question do realize definiteness but not via an article system, the L2er must discover that a [ \pm definite] feature is realized on English the and $a$. Numerous studies have reported difficulties involving article acquisition, including problems in mapping semantic features appropriately. Ionin, Ko and Wexler (2004) have shown that L2ers whose L1s lack articles fluctuate between choosing $[ \pm$ definite $]$ or $[ \pm$ specific $]$ as the relevant feature that determines English article choice.

On the other hand, White and colleagues (Belikova et al., in press; White, 2008a; White et al., 2009) have shown that L2ers with Mandarin, Russian or Turkish as L1s successfully map the feature [ \pm definite] onto English articles and other determiners, such as demonstratives, possessives, and numerals. There is a well-known restriction on definiteness (known as the Definiteness Effect) in the existential there-insertion construction (Milsark, 1977), where 
indefinite DPs are permitted (see (10a, c, e)), while definite expressions are excluded (as in (10b, $\mathrm{d}, \mathrm{f})$ ).

(10) a. There seems to be a fly in my soup.

b. *There seems to be the fly in my soup.

c. There are some flies in my soup.

d. *There is every fly in my soup.

e. There isn't any salt in my soup.

f. *There isn't the salt in my soup.

Results from spontaneous production and from contextualized acceptability judgments show that L2ers perform very accurately as far as the Definiteness Effect is concerned. Restrictions on the incidence of definite DPs are observed, even though the L1s lack realization of a definiteness contrast through an article system and even in cases where the L1 and L2 differ in how the Definiteness Effect plays out; Turkish and Russian (unlike English) permit definite expressions in negative contexts like (10f). Furthermore, this knowledge is demonstrated by intermediate level learners as well as advanced.

\subsection{Syntax/morphology}

While the semantics/morphology interface in L2 has only been addressed relatively recently (see Slabakova 2008 for a detailed overview), investigation of the relationship between underlying syntax and overt morphology (syntax/morphology or syntax/lexicon) has been of long-standing, although often not couched in interface terms. An issue that has received considerable attention involves the fact that L2ers frequently show variability in their spontaneous production of inflectional morphology and function words, omitting these, or making inappropriate substitutions of one kind of inflection for another. In other words, realization of overt morphology is in some sense defective, as illustrated below. In (11a) (from Lardiere, 2007) we see that the same speaker (Patty) sometimes supplies and sometimes omits tense marking. The same is true for articles; compare (11b) and (11c) (from White, 2003), where it can be seen that the same speaker is inconsistent in article production. Sometimes, inflection is 
in fact produced but the form is inappropriate. For example, in (12), the infinitive occurs when the verb should be inflected for 2nd person singular (Prévost and White, 2000a).
a. ..went to school and learn English.
b. It is very hard to learn a language.
c. .. we should rent two-bedroom apartment. you buy-INF a banana

(12) du kaufen eine Banane

At the same time, L2ers are highly accurate on syntactic properties normally associated with functional categories and projections. Lardiere $(1998,2007)$ shows that Patty is totally accurate on nominative case assignment (a property dependent upon Infl), as well as showing other evidence of 'intact' syntax.

A fruitful line of investigation has attempted to explain such behaviour in terms of problems in mapping between underlying morphosyntactic features and their morphophonological spellouts (Lardiere 1998, 2000), in other words, an interface problem. Similarly, proponents of the Missing Surface Inflection Hypothesis (Haznedar and Schwartz, 1997; Prévost and White, 2000a, b) argue that L2ers appropriately represent features at an abstract level, attributing failure to produce consistent inflection to temporary difficulties in accessing the relevant lexical items by which inflection is realized, particularly when speaking.

The assumption is that, when inflection or function words are missing, they are missing only at a surface level; at an abstract level they are appropriately represented (Haznedar and Schwartz, 1997; Lardiere, 1998; Prévost and White, 2000a, b; amongst others). Failure to produce verbs inflected for tense, in other words, is not indicative of a defective grammatical representation, contra theories such as the Representational Deficit Hypothesis of Hawkins and colleagues (e.g. Hawkins and Liszka, 2003). Rather, a tense feature is represented in the syntax but the learner fails to consistently link this feature to the particular form /-ed/ by which it is realized in English. Instead, the lexicon supplies something else, often an uninflected default form. 
A recent extension of the mapping explanation of non-native performance at the syntax/morphology interface is offered by Lardiere $(2008,2009)$, who proposes that L2 acquisition involves the need to reconfigure morphosyntactic features (both syntactic and semantic). In many cases, the arrangement of features, and mapping from features to lexical items, differs between the L1 and the L2, such that L2 learners will be faced with having to assemble or map features into new formal configurations. It is this reassembly that constitutes the learning problem and may lead to failure to produce appropriate morphology. In other words, linguistic representations are implicated: features have to be reconfigured before they can be mapped onto L2 forms in a native-like fashion.

\subsection{Phonology/morphology}

The final interface to be considered here is the phonology/morphology interface, which has recently been invoked to explain variability in production of inflectional morphology and function words. Goad and White $(2004,2006)$ argue that even when L2 morphosyntax has been acquired, such that the relevant features are appropriately represented in the interlanguage grammar, configured in relevant ways, there is influence from L1 prosodic structures. In other words, the interface between syntactic and prosodic representations leads to non-target outputs in production (resulting in omission or stressing of functional morphology). Goad and White advance the Prosodic Transfer Hypothesis, which states that interlanguage production of morphology typically associated with tense, agreement, number, and determiners, is constrained by L1 prosodic structure and that prosodic representations which happen to be absent from the L1 are particularly hard (or even impossible in some cases) to build in the interlanguage grammar.

For example, Goad et al. (2003), Goad and White (2006) and White (2008b) investigate the L2 English of Mandarin speakers. In terms of overt morphology, Mandarin lacks realization of tense and agreement; in terms of prosodic structure, Mandarin lacks adjunction to the PWd. Goad and colleagues show that Mandarin speakers exhibit linguistic performance consistent with the representation of a morphosyntactic tense feature in their interlanguage grammar, as shown 
by their behaviour on a variety of tasks, including sentence completion and grammaticality judgments. At the same time, some learners have problems in organizing inflection into the prosodic structure required for target-like production in English (namely, PWd adjunction). In consequence, they delete regular inflection in production. In some cases, they are able to prosodify English tense by means of a structure available in the L1 (involving a PWd-internal representation); as a result, for example, they are able to produce irregular past tense forms when they cannot consistently produce regulars. Goad and White (2006) show that PWd adjunction is eventually acquired, i.e., that failure to acquire this representation does not prove to be a permanent source of non-native performance.

\subsection{All of the above: multiple interfaces - the case of scrambling}

Ultimately, any linguistic phenomenon involves multiple interfaces. We have already seen that it is not always obvious which interface is involved in any particular case. For example, in the case of clitic doubling, are we dealing with syntax/discourse or syntax/semantics/discourse? In the case of indeterminate expressions in Chinese, Japanese and Korean, are we dealing with syntax/semantics or semantics/morphology or both?

Hopp (2007) considers the interaction of multiple interfaces on scrambling in L2 German. Like Sorace and colleagues, Hopp is interested in ultimate attainment. As he points out, while the interaction of topic and focus with word order at the syntax/discourse interface has been subject to extensive investigation in the L2 literature, scrambling has received less attention. Scrambling is a phenomenon permitted in a number of languages whereby arguments can be reordered under certain conditions. Hopp (2007: 94) lists a number of interfaces that impinge on scrambling in German: syntax/morphology (case and word order), syntax/semantics (interpretive constraints on the scrambling of indefinites), syntax/discourse (information structural conditions on scrambling). ${ }^{6}$ The following examples (from Hopp, 2007) illustrate

\footnotetext{
${ }^{6}$ Hopp adds one other interface (syntax/lexicon) which I omit from discussion. One can also add the phonology/syntax/discourse interface, since focus, which impinges on scrambling, is realized by means of prosodic effects in Germanic; see (13e, f).
} 
some of these interactions. In (13a) the embedded clause is in the standard SOV order, whereas in (13b) the object has scrambled over the subject; case marking stays constant while word order varies. In the unscrambled (13c), the indefinite DP (einen Hausbesetzer) can have either a specific or a non-specific interpretation; in (13d), on the other hand, where the indefinite has scrambled over an adverbial, it can only be interpreted as specific. (13e), a focalized NP ('den SOHN') appears in canonical position, whereas in (13f) it has scrambled over the subject, such that the focalized DP precedes the non-focalized one, yielding a somewhat degraded sentence.

a. Maria glaubt, dass der Vater den Wagen kauft.

Mary thinks that the-NOM father the-ACC car buys

'Maria thinks that the father is buying a car.'

b. Maria glaubt, dass den Wagen der Vater kauft.

Mary thinks that the-ACC car the-NOM father buys

'Maria thinks that the father is buying a car.'

c. .... dass ich gestern einen Hausbesetzer gesprochen habe.

.... that I yesterday a-ACC squatter spoken have

'... that I talked to a squatter yesterday.'

d. .... dass ich einen Hausbesetzer gestern gesprochen habe.

.... that I a-ACC squatter yesterday spoken have

'... that I talked to a squatter yesterday.'

e. .... dass der Vater den SOHN beschimpt.

.... that the-NOM father the-ACC son tells-off

'... that the father tells off the son'

f. ?.... dass den SOHN der Vater beschimpt.

.... that the-ACC son the-NOM father tells-off

'... that the father tells off the son'

Hopp investigates L2 performance on these interface phenomena. He conducted an intricate series of experiments on German scrambling with advanced and near-native German L2ers whose L1s were English (a language without scrambling), Dutch and Russian (both of which permit scrambling, though not in identical fashion to German). Subjects were tested by means of offline and online tasks (timed and untimed grammaticality judgments, picture 
description, self-paced reading). Hopp shows that some of the groups converge on native speaker performance for some of the interfaces. Concentrating only on the near-native results here, as far as syntax/morphology is concerned, all three near-native groups converged on the relevant properties (with the exception of judgments of case violations under time pressure, which only the Russian-speakers succeeded at). At the syntax/discourse interface, the English and Russian groups converged on native performance, both offline and online, whereas the Dutch speakers did not. As for syntax/semantics, none of the near-native groups was successful as far as restrictions on interpretation of scrambled indefinites was concerned. Hopp proposes that differences in performance, where they occur, are attributable to computational complexity. The processing of interface information associated with scrambling induces a computational burden (in some cases interacting with L1 effects) which results in non-native performance, even when the interface phenomena in question have in fact been acquired. Whether or not this explanation turns out to be correct, a crucial point illustrated by the case of scrambling is that it is rarely possible to identify some linguistic phenomenon as involving only one interface. Scrambling is surely not alone in requiring interactions at several different interfaces at once.

\section{$\underline{\text { 5. Discussion }}$}

To summarize so far, it does indeed appear to be the case that linguistic properties pertaining to interfaces are vulnerable in L2, whether in the course of acquisition or once a steady state has been achieved, even a near-native steady state. However, interfaces are not monolithic: it is not the case that all interfaces lead to difficulties, it is not the case that all phenomena at a particular interface are necessarily problematic, it is not the case that acquisition failure is inevitable. Instead, at the syntax/discourse interface, for example, the doubling of a topic by means of a clitic is sometimes problematic (Valenzuela 2005, 2006) and sometimes not (Ivanov 2009); at the syntax/semantics interface, subtle interpretive differences depending on L2 word order are acquirable (Dekydtspotter and colleagues), whereas subtle interpretive differences depending on L2 morphology are much harder to acquire (Choi and Lardiere, 2006; 
Umeda 2008). Neither version of Interface Hypothesis, as originally formulated, works for the range of data that we have examined.

One possibility, of course, is that variation in results across the studies discussed above reflects nothing more than experimental methodology. It is certainly true that some differences reported with respect to the same phenomenon are likely attributable to methodological differences. For example, as we have seen, with respect to the subtle interpretive contrasts related to position of adjectives in Romance languages, Coppieters (1987) reports that nearnative speakers fail to acquire these contrasts, in contrast to Anderson (2008) and Rothman et al. (2010). As mentioned above, only the latter studies included contexts in their tasks, which clearly assisted L2ers to reach the relevant interpretations.

If it turned out that all inconsistencies between results on interface phenomena could be attributed to such task-based differences, this would not be particularly illuminating as far as our understanding of the status of interfaces in L2 is concerned. However, there are cases where methodology clearly cannot be invoked to explain differences in the results. For example, in her investigation of clitic doubling, Parodi (2009) had learners of two different L2s taking the same task but performing differently. Other reported differences in performance on clitic doubling (Valenzuela 2005, 2006 versus Ivanov 2009) appear to reflect differences in the range of phenomena tested, more than task-specific details. And some well-studied interface phenomena, for example, overuse of overt subjects, reveal themselves as problematic across a range of different methodologies; indeed this is something that Belletti et al. (2007) are careful to show.

Assuming, then, that problems at interfaces reflect more than just methodological differences between various studies, let us consider the nature and source of the difficulties that L2ers experience. On the one hand, they have been argued to reflect L2ers' linguistic representations. L2ers may fail to represent certain properties at all, or represent them in a nonnative way, sometimes with permanent L1 effects in their interlanguage representations. Some of the cases considered above concern issues of representation, often involving grammatical features. For example, as far as syntax/discourse is concerned, a feature like [ \pm topic shift] is 
presumably represented somewhere; L2ers either do not acquire the feature, or its properties are in some way underspecified (Sorace, 2003, 2009), leading to occasional breakdown at this interface. Similarly, as far as clitics are concerned, at least some near-native L2ers appear not to include a [+specific] feature in their representation of clitics (Valenzuela, 2005, 2006). As far as semantics/morphology and syntax/morphology are concerned, both the Bottleneck Hypothesis (Slabakova, 2008) and the Feature Reassembly Hypothesis (Lardiere, 2009) suggest that L2ers may be unable to group features together appropriately for the L2 when the L1 maps features to forms in a different way, so that representations fail to be native-like. As for phonology/morphology, according to the Prosodic Transfer Hypothesis (Goad and White, 2004, 2006), L2ers are unable to represent certain aspects of L2 prosodic structure, instead resorting to L1 representations. At the same time, their morphosyntactic representations are assumed to be appropriate for the L2, resulting in discrepancies between different levels of representation.

On the other hand, some researchers have argued that breakdown at the interfaces does not reflect representational differences between L2 and native speaker grammars. Rather, processing pressures are implicated, the idea being that L2ers have less efficient processing resources (not necessarily different ones) which are more affected by realtime computational considerations than is the case for native speakers, such that they are not always able to access the relevant linguistic representations. Such explanations have been advanced to account for differences between L2ers and native speakers at several interfaces. For example, as far as the syntax/discourse interface is concerned, Belletti et al. (2007) speculate that problems with the realization of focus exhibited by near-native speakers of Italian may be attributable to unsystematic use of a low focus projection. In other words, the issue is not the representation of a focus projection as such but systematic access to that representation. At the semantics/pragmatics interface, Slabakova (2007, in press) and Lieberman (2009) suggest that scalar implicatures are generally computed appropriately but that computational complexity can impede the computation. At the syntax/morphology interface, according to the Missing Surface Inflection Hypothesis (Prévost and White, 2000a, b), L2ers have appropriate representation of 
morphosyntactic features but cannot necessarily access these representations when producing speech. Finally, Hopp (2007) proposes the Fundamental Identity Hypothesis, whereby nonnative and native grammatical representations are identical, as well as processing mechanisms. However, computational complexity can impinge on how well L2ers are able to process certain interface phenomena.

An interesting question that arises in the context of representational versus processing explanations of interface difficulties is the extent to which each of type of explanation expects communication breakdown. If L2ers represent certain linguistic properties in a way that differs from native speakers, this suggests that they might have problems not just in production but also in comprehension. On the other hand, if their problems relate to computational pressures on accessing their underlying (L2-like) linguistic representations, then L2ers might perhaps be expected to have greater production problems (causing possible confusion to their interlocutors) and lesser comprehension problems (not causing problems to themselves). For example, considering the syntax/morphology interface, interpretive difficulties may result for the hearer, because of omission or mispronunciation of certain morphology, and yet the L2 speaker knows exactly what he or she wants to convey, and can appropriately interpret native speaker production. On the other hand, considering the syntax/discourse interface, if underspecification of features like [ \pm topic shift] or focus projections is implicated, then L2ers should exhibit both production and comprehension problems, as reported by Sorace and colleagues.

In conclusion, just as interfaces have turned out not to be monolithic, there is no reason to assume that there is only one source of difficulty at the interfaces, either non-native grammatical representations or non-native processing. There may, indeed, be multiple explanations of L2ers' problems, including different sources for different interfaces, or for different linguistic phenomena, or for different levels of L2 proficiency. 


\section{References.}

Anderson, B., 2008. Forms of evidence and grammatical development in the acquisition of adjective position in L2 French. Studies in Second Language Acquisition 30, 1-29.

Belikova, A., Hagstrom, P., Kupisch, T, Özçelik, Ö., White, L., in press. Definiteness in positive and negative existentials in the L2 English of Russian speakers. In: Costa, J. Castro, A., Lobo, M., Pratas, F. (Eds.), Proceedings of GALA 2009. Cambridge Scholars Publishing, Cambridge, UK.

Belletti, A. (Ed.), 2004. Structures and beyond: the cartography of syntactic structures, Vol 3. Oxford University Press, Oxford, UK.

Belletti, A., Bennati, E., Sorace, A., 2007. Theoretical and developmental issues in the syntax of subjects: evidence from near-native Italian. Natural Language and Linguistic Theory 25, 657-689.

Belletti, A., Leonini, C., 2004. Subject inversion in L2 Italian. In: Foster-Cohen, S., Sharwood Smith, M., Sorace, A., Ota. M. (Eds.), Eurosla Yearbook 4. John Benjamins, Amsterdam, pp. 95-118.

Birdsong, D., 1992. Ultimate attainment in second language acquisition. Language 68, 706-755.

Büring, D., 2007. Semantics, intonation, and information structure. In: Ramchand, G., Reiss, C. (Eds.), The Oxford handbook of linguistic interfaces. Oxford University Press, Oxford, UK, pp. 445-473.

Choi, M.-H., Lardiere, D., 2006. The interpretation of wh-in-situ in Korean second language acquisition. In: Belletti, A., Bennati, E., Chesi, C., Di Domenico, E., Ferrari, I. (Eds.), Language acquisition and development: Proceedings of GALA 2005. Cambridge Scholars Publishing, Cambridge, UK.

Chomsky, N., 1995. The minimalist program. MIT Press, Cambridge, MA.

Chomsky, N., 2001. Derivation by phase. In: Kenstowicz, M. (Ed.), Ken Hale: a life in language. MIT Press, Cambridge, MA, pp. 1-52).

Coppieters, R., 1987. Competence differences between native and near-native speakers. Language 63, 544-573.

Dekydtspotter, L., Hathorn, J., 2005. Quelque chose. de remarquable in English-French acquisition: mandatory, informationally encapsulated computations in second language interpretation. Second Language Research 21, 291-323.

Dekydtspotter, L., Sprouse, R., 2001. Mental design and (second) language epistemology: adjectival restrictions of wh-quantifiers and tense in English-French interlanguage.

Second Language Research 17, 1-35.

Dekydtspotter, L., Sprouse, R., Anderson, B., 1997. The interpretive interface in L2 acquisition: the process-result distinction in English-French interlanguage grammars. Language Acquisition 6, 297-332.

Dekydtspotter, L., Sprouse, R., Swanson, K., 2001. Reflexes of mental architecture in secondlanguage acquisition: the interpretation of combien extractions in English-French interlanguage. Language Acquisition 9, 175-227.

Dekydtspotter, L., Sprouse, R., Thyre, R., 2001. The interpretation of quantification at a distance in English-French interlanguage: domain specificity and second-language acquisition. Language Acquisition 8, 265-320.

Erteschik-Shir, N., 2007. Information structure. Oxford University Press, Oxford, UK. 
Feeney, A., Scrafton, S., Duckworth, A., Handley, S., 2004. The story of some: everyday pragmatic inference by children and adults. Canadian Journal of Experimental Psychology 58, 121-132.

Gillingham, G., 2007. Not every implicature is computed by default: investigations into the effect of linguistic context on the rate of computation of scalar implicature. Unpublished Honours thesis, McGill University.

Goad, H., White, L., 2004. Ultimate attainment of L2 inflection: effects of L1 prosodic structure. In: Foster-Cohen, S., Sharwood Smith, M., Sorace, A., Ota. M. (Eds.), Eurosla Yearbook 4. John Benjamins, Amsterdam, pp. 119-145.

Goad, H., White, L., 2006. Ultimate attainment in interlanguage grammars: a prosodic approach. Second Language Research 22, 243-268.

Goad, H., White, L., Steele, J., 2003. Missing inflection in L2 acquisition: defective syntax or L1-constrained prosodic representations? Canadian Journal of Linguistics 48, 243-263.

Grice, P., 1989. Studies in the way of words. Harvard University Press, Cambridge, MA.

Gürel, A., 2006. L2 acquisition of pragmatic and syntactic constraints in the use of overt and null subject pronouns. In: Slabakova, R., Montrul, S., Prévost, P. (Eds.), Inquiries in linguistic development: in honor of Lydia White. John Benjamins, Amsterdam, pp. 259-282.

Hawkins, R., Liszka, S., 2003. Locating the source of defective past tense marking in advanced L2 English speakers. In: van Hoet, R., Hulk, A., Kuiken, F., Towell, R. (Eds.), The lexicon-syntax interface in second language acquisition. John Benjamins, Amsterdam, pp. 21-44).

Haznedar, B., Schwartz, B.D., 1997. Are there optional infinitives in child L2 acquisition? In: Hughes, E., Hughes, M., Greenhill, A. (Eds.), Proceedings of the 21st Annual Boston University Conference on Language Development. Cascadilla Press, Somerville, MA, pp. 257-268.

Hertel, T. J., 2003. Lexical and discourse factors in the second language acquisition of Spanish word order. Second Language Research 19, 273-304.

Hopp, H., 2007. Ultimate attainment at the interfaces in second language acquisition. $\mathrm{PhD}$ dissertation, Groningen University. Groningen Dissertations in Linguistics 65.

Horn, L., 1972. On the semantic properties of logical operators in English. Unpublished doctoral dissertation, University of California, Los Angeles.

Hulk, A., Müller, N., 2000. Bilingual first language acquisition at the interface between syntax and pragmatics. Bilingualism: Language and Cognition 3, 227-244.

Ivanov, I., 2009. Topicality and clitic doubling in L2 Bulgarian: a test case for the interface hypothesis. In: Bowles, M., Ionin, T., Montrul, S., Tremblay, A. (Eds.), Proceedings of the 10th Generative Approaches to Second Language Acquisition Conference (GASLA 2009). Cascadilla Proceedings Project, Somerville, MA, pp. 17-24.

Ionin, T., Ko, H. Wexler, K., 2004. Article semantics in L2 acquisition: the role of specificity. Language Acquisition 12, 3-69.

Jackendoff, R., 1972. Semantic interpretation in generative grammar. MIT Press, Cambridge, MA.

Jackendoff, R., 1997. The architecture of the language faculty. MIT Press, Cambridge, MA.

Jackendoff, R., 2002. Foundations of language: Brain, meaning, grammar, evolution. Oxford University Press, Oxford, UK. 
Jackendoff, R., 2007. Language, consciousness, culture: Essays on mental structure. MIT Press, Cambridge, MA.

Jaeggli, O., 1982. Topics in Romance syntax. Dordrecht: Foris.

Lardiere, D., 1998. Case and tense in the 'fossilized' steady state. Second Language Research 14, $1-26$.

Lardiere, D., 2000. Mapping features to forms in second language acquisition. In: J. Archibald (ed.), Second language acquisition and linguistic theory. Blackwell, Oxford, UK, pp. 102129.

Lardiere, D., 2005. On morphological competence. In: Dekydtspotter, L., Sprouse, R., Liljestrand, A. (Eds.), Proceedings of the $7^{\text {th }}$ Generative Approaches to Second Language Acquisition Conference (GASLA 2004), Cascadilla Proceedings Project, Somerville, MA, pp. 178-192).

Lardiere, D., 2007. Ultimate attainment in second language acquisition. Lawrence Erlbaum, Mahweh, N.J..

Lardiere, D., 2008. Feature assembly in second language acquisition. In: Liceras, J., Zobl H., Goodluck, H. (Eds.), The Role of Features in Second Language Acquisition, Lawrence Erlbaum, Mahweh, N.J., pp. 106-140.

Lardiere, D., 2009. Some thoughts on the contrastive analysis of features in second language acquisition. Second Language Research 25, 173-227.

Liceras, J., 1988. Syntax and stylistics: more on the pro-drop parameter. In: Pankhurst, J., Sharwood Smith, M., Van Buren, P. (Eds.), Learnability and second languages: a book of readings. Foris, Dordrecht, pp. 71-93.

Lieberman, M., 2009. Necessary interpretation at the syntax/pragmatics interface: L2 acquisition of scalar implicatures. Paper presented at the Workshop on Mind Context Divide: Language Acquisition and Interfaces of Cognitive Linguistic Modules. University of Iowa, April 2009.

López, L., 2009. A derivational syntax for information structure. Oxford University Press, Oxford, UK.

Lozano, C., 2006. Focus and split-intransitivity: the acquisition of word order alternations in non-native Spanish. Second Language Research 22, 145-187.

Lozano, C., 2009. Selective defictis at the syntax-discourse interface. In: Snape, N., Leung, Y.K. I., Sharwood Smith, M. (Eds.), Representational deficits in SLA: Studies in honor of Roger Hawkins. John Benjamins, Amsterdam, pp. 127-166.

Milsark, G. L., 1977. Toward an explanation of certain pecularities of the existential construction in English. Linguistic Analysis 3, 1-29.

Montalbetti, M., 1984. After binding: on the interpretation of pronouns. Unpublished Ph.D. thesis, MIT.

Montrul, S., 2004. Subject and object expression in Spanish heritage speakers: a case of morphosyntactic convergence. Bilingualism: Language and Cognition 7, 125-142.

Montrul, S. Louro, C. R., 2006. Beyond the syntax of the null subject parameter. In: Torrens, V., Escobar, L. (Eds.), The acquisition of syntax in Romance languages. John Benjamins, Amsterdam, pp. 401-418.

Noveck, I., 2001. When children are more logical than adults: experimental investigations of scalar implicatures. Cognition 78, 165-188. 
Paradis, J. Navarro, S., 2003. Subject realization and crosslinguistic interference in the bilingual acquisition of Spanish and English: what is the role of input? Journal of Child Language 30, 371-393.

Parodi, T., 2009. Clitic doubling and clitic left dislocation in Spanish and Greek L2 grammars. In: Snape, N., Leung, Y.-K. I., Sharwood Smith, M. (Eds.), Representational deficits in SLA: Studies in honor of Roger Hawkins. John Benjamins, Amsterdam, pp. 167-185.

Pérez-Leroux, A. T., Glass, W., 1997. OPC effects in the L2 acquisition of Spanish. In: PérezLeroux, A. T., Glass, W. (Eds.), Contemporary perspectives on the acquisition of Spanish. Volume 1: developing grammars. Cascadilla Press, Somerville, MA, pp. 149165.

Pérez-Leroux, A. T., Glass, W., 1999. Null anaphora in Spanish second language acquisition: probabilistic versus generative approaches. Second Language Research 15, 220-249.

Phinney, M., 1987. The pro-drop parameter in second language acquisition. In: Roeper, T., Williams, E. (Eds.), Parameter setting. Reidel, Dordrecht, pp. 221-238.

Prévost, P., White, L. , 2000a. Accounting for morphological variation in L2 acquisition: Truncation or missing inflection? In: Friedemann, M.A., Rizzi, L. (Eds.), The acquisition of syntax: Issues in comparative developmental linguistics. Longman, Harlow, UK, pp. 202-234.

Prévost, P., White, L., 2000b. Missing surface inflection or impairment in second language acquisition? Evidence from tense and agreement. Second Language Research 16, 103 133.

Ramchand, G., Reiss, C., (Eds.), 2007. The Oxford Handbook of Linguistic Interfaces. Oxford University Press, Oxford, UK.

Reinhart, T., 2006. Interface Strategies: Optimal and Costly Computations. MIT Press, Cambridge, MA.

Rizzi, L., 1982. Issues in Italian Syntax. Foris, Dordrecht.

Rizzi, L., 1997. The fine structure of the left periphery. In: Haegeman,L. (Ed.), Elements of Grammar: Handbook in Generative Syntax pp. 281-337). Kluwer, Dordrecht, pp. 281337.

Roberts, L., Gullberg, M. Indefrey, P., 2008) Online pronoun resolution in L2 discourse: L1 influence and general learner effects. Studies in Second Language Acquisition 30, 333 357.

Rothman, J., 2009. Pragmatic deficits with syntactic consequences? L2 pronominal subjects and the syntax-pragmatics interface. Journal of Pragmatics 41, 951-973.

Rothman, J., Judy, T., Guijarro-Fuentes, P., Pires, A., 2010. On the (un)ambiguity of adjectival modification in Spanish determiner phrases. Studies in Second Language Acquisition 32, 47-77.

Schaeffer, J., 2000. Direct Object Scrambling and Clitic Placement: Syntax and Pragmatics. John Benjamins, Amsterdam.

Serratrice, L., Sorace, A., Paoli, S., 2004. Crosslinguistic influence at the syntax-pragmatics interface: subjects and objects in English-Italian bilingual and monolingual acquisition. Bilingualism: Language and Cognition 7, 183-205.

Slabakova, R., 2007. Scalar implicatures in L2 acquisition. In: Caunt-Nulton, H., Kulatilake , S., Woo, I-h. (Eds.), Proceedings of the 31st Annual BUCLD. Cascadilla Press, Somerville, MA. 
Slabakova, R., 2008. Meaning in the Second Language. Mouton de Gruyter, Berlin.

Slabakova, R., 2009. What is easy and what is hard to acquire in a second language? In: CauntNulton, H., Bowles, M., Ionin, I., Montrul, S., Tremblay, A. (Eds.), Proceedings of the 10th Generative Approaches to Second Language Acquisition Conference (GASLA 2009) pp.280-294). Cascadilla Proceedings Project, Somerville, MA, pp.280-294.

Slabakova, R., in press. Scalar implicatures in second language acquisition. Lingua.

Slabakova, R., Ivanov, I., This issue. A more careful look at the syntax-discourse interface. Lingua.

Sorace, A., 2003. Near-nativeness. In: Doughty, C., Long, M. (Eds.), Handbook of Second Language Acquisition pp.130-151). Blackwell, Oxford, UK, 130-151.

Sorace, A., 2005. Selective optionality in language development. In: Cornips, L., Corrigan, K. P. (Eds.), Syntax and Variation: Reconciling the Biological and the Social. John Benjamins, Amsterdam, pp. 55-80.

Sorace, A., 2006. Gradedness and optionality in mature and developing grammars. In: Fanselow, G., Féry, C., Vogel, R., Schlesewsky, M. (Eds.), Gradience in Grammar. Oxford: Oxford University Press, pp. 106-123.

Sorace, A., 2007. Optionality at the syntax-discourse interface in near-native L2 grammars. Second Language 6.

Sorace, A., 2009. Pinning down the concept of interface. Plenary paper presented at the Workshop on Interfaces in L2 Acquisition, Lisbon, June 2009.

Sorace, A., Filiaci, F., 2006. Anaphora resolution in near-native speakers of Italian. Second Language Research 22, 339-368.

Sorace, A., Serratrice, L, 2009. Internal and external interfaces in bilingual language development: Beyond structural overlap. International Journal of Bilingualism 13: 195210.

Tedeschi, R., 2009. Acquisition at the Interfaces: a Case Study on Object Clitics in Early Italian. Unpublished $\mathrm{PhD}$ thesis, University of Utrecht.

Tsimpli, I.-M., Sorace, A., 2006. Differentiating interfaces: L2 performance in syntax-semantics and syntax-discourse phenomena. In:Bamman, D., Magnitskaia, T., Zaller, C. (Eds.), Proceedings of the 30th Annual BUCLD. Cascadilla Press, Somerville, MA, pp. 653-664.

Tsimpli, I.-M., Sorace, A., Heycock, C., Filiaci, F., 2004. First language attrition and syntactic subjects: a study of Greek and Italian near-native speakers of English. International Journal of Bilingualism 8, 257-277.

Umeda, M., 2008. Second Language Acquisition of Japanese Wh-Constructions. PhD dissertation, McGill University.

Valenzuela, E., 2005. L2 Ultimate Attainment and the Syntax-Discourse Interface: the Acquisition of Topic Constructions in Non-Native Spanish and English. PhD dissertation, McGill Univeristy.

Valenzuela, E., 2006. L2 end state grammars and incomplete acquisition of the Spanish CLLD constructions. In: Slabakova, R., Montrul, S., Prévost, P. (Eds.), Inquiries in Linguistic Development: in Honor of Lydia White. John Benjamins, Amsterdam, pp. 283-304.

White, L., 1985. The "pro-drop" parameter in adult second language learning. Language Learning 35, 47-62.

White, L., 2003. Fossilization in steady state L2 grammars: persistent problems with inflectional morphology. Bilingualism: Language and Cognition 6: 129-141. 
White, L., 2008a. Definiteness effects in the L2 English of Mandarin and Turkish speakers. In: Chan, H., Jacob, H., Kapia, E. (Eds.), Proceedings of the 32nd Annual Boston University Conference on Language Development. Cascadilla Press, Somerville, MA, pp. 550-561.

White, L. , 2008b. Some puzzling features of L2 features. In: J. Liceras, H. Zobl and H. Goodluck (Eds.), The Role of Features in Second Language Acquisition. Lawrence Erlbaum, pp. 301-326.

White, L. , 2009. Grammatical theory: interfaces and L2 knowledge. In: W. Ritchie and T. Bhatia (Eds.), The New Handbook of Second Language Acquisition. Emerald Group Publishing Limited, Leeds, UK, pp. 49-68.

White, L., Belikova, A., Hagstrom, P., Kupisch, T. Özçelik, Ö., 2009. Restrictions on definiteness in L2 English. In: Chandlee, J., Franchini,M., Lord, S., Rheiner, G.-M. (Eds.), Proceedings of the 33rd Annual Boston University Conference on Language Development. Cascadilla Press, Somerville, MA, pp. 622-633.

Yuan, B., 2008. Discrepancy in English speakers' L2 acquisition of Chinese wh-words as existential polarity words: the L1 dependent interface hypothesis. In: Slabakova, R., Rothman, J., Kempchinsky, P., Gavruseva, E. (Eds.), Proceedings of the 9th Generative Approaches to Second Language Acquisition Conference (GASLA 9). Somerville, MA: Cascadilla Proceedings Project, pp. 272-284.

Yuan, B., 2010. Domain-wide or variable-dependent vulnerability of the semantics-syntax interface in L2 acquisition? Evidence from wh-words used as existential polarity words in L2 Chinese grammars. Second Language Research 26: 219-260.

Zubizarreta, M. L., 1998. Prosody, Focus and Word Order. MIT Press, Cambridge, MA. 